\title{
Textualidades Contemporâneas: 0 realismo sedutor e sua configuração na dramaturgia brasileira
}

Martha Ribeiro ${ }^{1}$

Neste artigo trataremos de falar de textos e não de peças, buscando identificar em certas textualidades contemporâneas, neste caso a brasileira, seu comportamento diante daquilo que se nomeia como pós-moderno. Se uma das grandes ilusões modernas foi apresentar o teatro sem o teatro, em sua autonomia e emancipação, o que se seguiu, com o pós-moderno, foi o mergulho em todo tipo de hibridações e mestiçagem instituindo um tipo de realismo mais "afetivo"; uma teatralidade que denominamos "realismo sedutor".

Palavras-chave: Textualidades brasileiras; Teatro Pós-Moderno; Realismo sedutor

In this article we intend to talk about texts and not about plays, in search for an identification of a certain contemporary textuality, the Brazilian, its behavior facing what is called post-modernity. If one of the great modern illusions was to present a theater without theater in its autonomy and emancipation, what was followed with post-modernism, was a jump into any kinds of hybridation and mixed breeds, establishing a more "affective" kind of realism, a theatricality we call "seductive realism".

Key-words: Brazilian textualities; Post-Modern Theater; Seductive Realism

\footnotetext{
1 Diretora teatral e Professora Adjunta da Universidade Federal Fluminense, IACS - Departamento de Arte. Atuando também no Programa de Pós-Graduaçao em Estudos Contemporâneos das Artes (PPGCA) da instituição. Com doutorado em Teoria e História Literária pela Universidade Estadual de Campinas (2008), com período sanduiche na Università di Torino no DAMS. Desde 2008 vem anualmente realizando pesquisa de campo nas seguintes universidades italianas: Università degli Studi di Torino e Università di Milano, a convite dos professores Roberto Alonge e Paolo Bosisio respectivamente. Em 2013, a convite de Thomas Richards e Mario Biagini, irá acompanhar, como observadora, as atividades do Workcenter de Grotowski e Thomas Richards durante o Summer Intensive Program, em Pontedera, Itália.
} 
Que as palavras deixem de fazer "texto"...

Gilles Deleuze

Um manifesto de menos, 1978

Em seu "Manifesto de menos", Deleuze se debruça sobre a obra teatral de Carmelo Bene (1937-2002), ator, dramaturgo, cineasta e encenador italiano, para dali extrair alguns princípios, notadamente na via de interrupção da representação, que irão particularmente nos interessar neste ensaio que tem por objetivo refletir sobre certas tendências na dramaturgia nacional (brasileira) em seu confronto com o pós-moderno. Não se trata aqui de realizar uma antologia de obras de dramaturgia, selecionadas por algum dispositivo de poder, separando autores e produções, bem ou mal sucedidas, ao contrário. Nossa intenção é escapar do posicionamento histórico-ideológico de seleção, que reafirma as estruturas de um teatro consolidado, oficialmente constituído, ou da moda, para investigar certas textualidades apresentadas em certas cenas mais atuais do teatro brasileiro que corrobora com nosso pensamento a propósito de um realismo sedutor (estado que identificamos na arte teatral contemporânea enquanto resposta ao projeto moderno mais radical de emancipação da arte). Sem negar o real, e sem ser seu contrário, essa nova cena se institui colocando o real em jogo; e o jogo é um dos domínios da sedução.

Em seu artigo "La théâtralité en Avignon" (1998), Patrice Pavis revisita o conceito de teatralidade em seu "Dicionário de Teatro" (1996), questionando o termo na sua designação genérica de uma "especificidade" meio mística do teatro. A pluralidade de experiências, de teatralidades, observadas em Avignon, fez o teórico concluir que o termo, afastado de seu uso abstrato, permite, a partir de um método de análise que privilegie procedimentos cênicos, diagnosticar diferentes exemplos de teatralidade segundo o uso material das textualidades espetaculares (corpo, espaço, texto, visualidade). As muitas definições de teatralidade elencadas por Pavis indi- cam a impossibilidade de uma definição unívoca do termo, que se presta muito bem a descrever de forma pragmática diferentes aspectos do teatro contemporâneo hoje. Neste sentido, enquanto um conceito operatório, teatralidade indica a negação de uma teatralidade em si, mas também institui sua presença tangível, onipresente, em diferentes espetáculos. Neste ponto, Pavis faz uma restrição do termo no que tange as experiências de "performances culturais", opondo a esta teatralidade da vida cotidiana a teatralidade de procedimentos artísticos. Tomando partido do conceito de "teatralidade de efeitos e de procedimentos artísticos" de Pavis, iremos analisar duas experiências cênicas brasileiras, a peça radiofônica "Trilhas sonoras de amor perdidas" da Sutil Companhia, com direção de Felipe Hirsch e "Preferiria não?" de Denise Stoklos; espetáculos completamente distintos no uso da teatralidade, mas que realizam sua experiência cênica a partir de "um modo estético no tratamento do real", isto é, a partir de critérios estéticos que distinguem seus procedimentos da vida cotidiana, sem, no entanto, romper com a realidade que se conhece, criando uma zona intermediária, um espaço de passagem para duas diferentes configurações, o real e o imaginário. Esse tipo de tratamento dado à cena, denominamos Realismo Sedutor.

Tratemos primeiro de compreender o que identificamos como "textualidades", ou mais resumidamente, "texto", confrontado com a ideia de peça. E aqui entra uma provocação com a citação em epígrafe, pois, ao contrário do que poderia parecer a uma leitura desatenta, entendemos que o pensamento de Deleuze dialoga com o nosso, na exata medida em que nossos esforços se direcionam ao entendimento do texto contemporâneo como um texto que subtrai de seu organismo a hierarquia da literalidade dramática (internalizada no conceito de peça teatral). Propondo, na sua conformação, o uso de diferentes textos, que podem ser corporais, midiáticos, visuais, documentais, biográficos, etc., a textualidade contemporânea em seu viés sedutor 
não se quer representativa de um real unívoco, não se quer prisioneira de uma lógica representativa, mas também não se quer abismada do real, negando a representação para fundar um "próprio da arte". Problematizando a relação do teatro com o real, estabelecendo uma relação que não procede nem por transparência, de adequação a uma referência unívoca, e nem por opacidade total, de não-referencialidade a algo externo a ela, mas de jogo, o texto que nos interessa discutir aqui se realiza nas camadas do entre: entre a linguagem e o mundo, entre o ficcional e o real.

Como alerta Josette Féral em seu "Teatro, teoria y práctica: más allá de las fronteras" (2004), falar da relação do teatro com o real pode parecer problemático, na medida em que insinua a existência de um real unívoco, cognoscível e portanto representável, no entanto, desde os três mestres da suspeita - Marx, Freud, Nietzsche - entende-se que o real é, ele mesmo, o resultado de uma observação problemática, de uma construção, e de que sempre haverá um resto que nos escapa, pois, o real, já seria, ele mesmo, uma representação; o que não significa que compartilhamos a tese da "morte" do sujeito, ao contrário, o sujeito em seu confronto com o mundo, não é senhor do sentido, mas também não está ausente desse mundo, a representação ficcional, como a representação histórica, dirá Rancière, constroem "ficções", isto é, "rearranjos materiais dos signos e das imagens, das relações entre o que se vê e o que se diz, entre o que se faz e o que se pode fazer", e acrescenta: "O real precisa ser ficcionado para ser pensado" (2009, p. 58-59). Corroborando com essa ideia, destaca Tassinari: "A obra não imita uma visão nem imita em conformidade com uma visão, mas se comunica com o espectador numa espécie de face a face que tem no mundo em comum o seu solo e sua garantia. O que por sua vez, não abole a subjetividade do espectador. Sem ela não há obra, porque não haveria destino da obra" (2001, p.148).

A ideia de textualidades como indicativo de um processo construtivo de sentido, em detrimento da ideia de peça, produto e modo de fazer específico da arte dramática, corresponde a uma mudança de paradigma nas artes da cena, como identificado por Hans Thies-Lehmann em seu "Teatro pós-dramático" (2007), que também significa uma mudança de regime da arte, como identificado por Rancière em "A partilha do sensível": se no regime representativo, a arte estava sujeita a critérios poéticos e de fabricação que definiam a imitação, no regime estético o que define a arte não será o seu modo de fazer, sua especificidade, mas o modo de ser sensível.

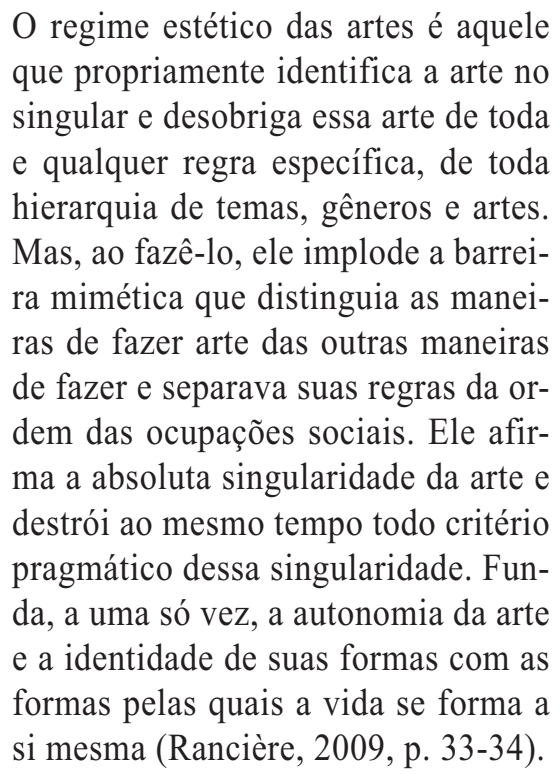

Esse estado de interrupção da representação, no sentido paradigmático da equação teatro=drama, construção linear da fábula "pela necessidade e verossimilhança", não significa, conforme atestado por Rancière, o abandono do realismo (figurativo), ao contrário, mas também não significa a "valorização da semelhança, mas a destruição dos limites dentro dos quais ela funcionava" (2009: 35). Todas as hierarquias do sistema representativo, em sua organização de pares opositivos (comédia/tragédia; alto/baixo; drama/épico; antigo/moderno), serão subvertidas, interrompidas, suprimidas, com o objetivo de reinterpretar, de escavar, de fazer uma releitura do passado, imprimindo uma relação muito mais branda com as heranças clássicas, misturando as artes, os gêneros, 
embriagando-se com diferentes suportes, com novas combinações, arruinando enfim com o projeto moderno de separação das artes e da conquista da forma pura, ou de uma essência própria ao teatro, que ao final do século XIX tanto inspiraram os reformadores da cena, de Meyerhold a Artaud.

Essa rejeição à teatralidade se observa ainda mais intensamente com a prática e os estudos teóricos ligados a performance, mesmo nos anos oitenta, com uma clara rejeição aos aspectos miméticos, discursivos e narrativos do teatro tradicional, privilegiando seu aspecto de evento. Marvin Carlson no livro "Performance, uma introdução crítica", analisa que a despeito de caracterizar a arte da performance como um movimento pós-moderno, seu desenvolvimento inicial e suas raízes estavam claramente ligadas ao formalismo da arte moderna, e que "longe de ser um fenômeno pós-moderno, estava, em sua insistência na horizontalidade e na abstração, em débito profundo para com todo o movimento de arte moderno" (Carlson apud Mehta, 2010, p.145). Carlson continua sua análise observando que a ênfase na presença, na imanência, instituída pela abordagem fenomenológica da performance, que procurava transcender a história, torna-se problemática com o pós-estruturalismo, que vai aceitar a relação contingente e de choque entre a arte e o mundo. O que está em jogo é a suspeita de que toda forma de presença é já uma representação, ou seja, presentificação de uma ausência: "A presença, para ser presença e presença a si, começou já sempre a representar-se" (Derrida, 1971, p.174).

Derrida, em seus dois ensaios fundamentais, "A palavra soprada" e "O teatro da crueldade e o fechamento da representação", vai refutar a ideia de teatro de Artaud, entendendo sua potência revolucionária, mas rejeitando sua tentativa de escapar à representação, na busca de um sentido original, não contaminado: "Artaud desejou também a impossibilidade do teatro, quis apagar ele próprio o palco" (Derrida, 1971, p.175) Derrida vai dizer que essa tentativa é impossível, pois toda ação sempre estará envolvida com a repetição, não sendo possível a experiência da presença pura, não mediada. Mas observa-se que Derrida não vai simplesmente substituir uma estética da presença por uma estética da ausência, a rejeição à ideia de presença pura, instituindo a repetição (e portanto o teatro) é, no projeto de Derrida, um jogo entre ausência e presença. Esse jogo recusa a estabilidade da forma, operando na diferença, tratando termos como teatro e performance de forma radicalmente diferente, sugerindo um eterno jogo entre esses dois termos: um entrelugar entre presença e ausência.

Critica ao sistema de representação, mas recusa à esterilidade abstrata do modernismo; interrupção das estruturas codificadas da representação, mas uso da narrativa; é neste jogo de forças entre essas duas realidades - códigos teatrais e fluxos energéticos da performance - que identificamos em Hirsch e Stoklos o realismo sedutor.

Interromper não é mesma coisa que destruir, ou fazer desaparecer; interromper é parar momentaneamente o progresso de algo, é a pausa. E a pausa é a crítica, aquilo que deriva de algo, que perturba certa ordem anterior. E a perturbação só é possível porque a pausa, que é uma incisão, opera pela descontinuidade, rompendo com a forma e instituindo a diferença. Se não é possível purgar a arte do "teatral", promovendo experiências não contaminadas, na ideia de interrupção, como dirá Lehmann, "os vários elementos, agora dissociados, podem ser construídos de outra maneira" (2008, p. 239). E é neste sentido que compreendemos a interrupção, como desconstrução dos códigos, das estruturas e do modo de fazer do dramático, uma não submissão à lógica representativa, sem, no entanto, instituir a utopia de uma pureza antirepresentativa. Interromper não é romper definitivamente, é a pausa crítica para reinterpretar, rearranjar, desobrigando a arte teatral de toda e qualquer regra, de toda especialidade, instituindo a diferença na embriaguez de diferentes textualidades. 
A análise da interrupção no trabalho de Carmelo Bene, por Deleuze, aponta na direção da produção de algo novo, a partir da repetição e não da representação - insiste o filósofo -, a partir de certas operações de subtração e de amputação executadas pelo homem de teatro Bene em peças originais. Na leitura de Deleuze o teatro de Carmelo Bene não é um teatro da representação, e sim um teatro da repetição, isto é, da transgressão, de reversão da maneira de fazer, que se institui contra a lei: "Se CB [Carmelo Bene] tem frequentemente necessidade de uma peça originária, não é para fazer dela uma paródia, seguindo a moda, nem para acrescentar literatura à literatura. Pelo contrário, é para subtrair a literatura, por exemplo subtrair o texto, uma parte do texto, e ver o que acontece" (Deleuze, 2010: 29). Na peça "um Hamlet de menos", Carmelo Bene irá subtrair Romeu, construindo uma nova peça, onde Mercúcio se torna o protagonista. O que se assiste no palco é a construção deste personagem que na peça de Shakespeare morre cedo. No caso de Bene, toda a peça é a constituição (fabricação) deste personagem, "a peça acaba com a constituição do personagem, ela só tem como objeto o processo dessa constituição [...] Ela para com o nascimento [do personagem], enquanto habitualmente é na morte que se para". (2009, p. 31).

O que gostaríamos de chamar atenção neste ponto, na abordagem deleuziana sobre a obra de Bene, é que nas operações de amputação em suas peças ["um Hamlet de menos", "S.A.D.E."; "Ricardo III"], o artista $\mathrm{CB}$, nos três casos, irá proceder por interrupção da própria forma dramática, se afastando do sistema representacional normativo. Ao interromper com o domínio de uma prática organizativa de produção, ele renega a ideia de estrutura dramática, de representação da forma instituída, constituindo uma nova potencia teatral (identificada por Deleuze como não-representativa). É importante dizer que no teatro de Bene não há diálogos, ou conflitos, são vozes simultâneas que se sobrepõe no palco; o que o artista propõe em seu lugar, observa Deleuze, substituindo a representação do conflito (pois como bem observa o filósofo, todo conflito já está normalizado e codificado, como um produto), não é um psicodrama, ou um teatro esteta, abstrato, ou místico, o projeto de Bene é escapar do padrão majoritário, isto é, da representação-padrão, do modelo, constituindo "uma figura da consciência minoritária", isto é, "desde que a minoria não represente nada de regionalista; mas também nada de aristocrático, de abstrato, nem de místico" (Deleuze, 2010, p. 64). Isto é, figuras que a história não levou em conta.

Essa interrupção da estrutura formal do drama estabelece um novo regime das artes, como identificado por Rancière em seu "A partilha do sensível", o regime estético, onde não é mais possível falar da arte enquanto ordenadora de ações, devedora de uma racionalidade dramática. Desobrigada de toda doutrina, inclusive do radicalismo antimimético dos arautos da modernidade artística, mas destituindo as regras de funcionamento das hierarquias da representação, ela nega qualquer ideia de unicidade ou de pureza, preferindo os entrelaçamentos textuais: "a noção de modernidade parece, assim, como inventada de propósito para confundir a inteligência das transformações da arte e de suas relações com as outras esferas da experiência coletiva" (Rancière, 2009, p. 37). Desta feita, a arte teatral, no regime estético, será entendida aqui enquanto combinação entre performatividade e teatralidade. Ao mesmo tempo autônoma e heterônoma, ela realiza sua autonomia a partir de uma experiência de heteronomia, de relação entre procedimentos teatrais e de performance, ela é arte e também não-arte; ao mesmo tempo em que realiza uma cisão, uma interrupção na estrutura representacional, em proveito do instantâneo e da ação real, isto é, da performatividade, ela não irá abandonar procedimentos de teatralidade - uma certa "artisticidade" que a torna distinta da vida cotidiana.

Aqui se pode pensar no Living Theatre, na dança teatro de Pina Bausch, no 
Théâtre du Soleil, no Grupo Oficina de Zé Celso, no teatro performativo de Robert Lepage, em alguns espetáculos de Felipe Hirsch e nos últimos trabalhos de Denise Stoklos; menos preocupados com o paradigma modernista do que com a mistura de gêneros e de suporte, estas experiências cênicas propõem uma concepção de arte que busca diluir as fronteiras entre o teatro e a performance, valem-se de recursos performativos, mas não veem problema algum em usar da narrativa ou do testemunho autobiográfico, tornando a experiência cênica reconhecível.

Refletindo sobre os caminhos da cena brasileira contemporânea, onde neste artigo usamos como exemplo os espetáculos "Preferiria não?" e "Trilhas sonoras de amor perdidas", respectivamente de Denise Stoklos [DS] e de Felipe Hirsch [FH], observa-se um retorno à narrativa, de revalorização da experiência vivencial, íntima, da vida ordinária. Ambos os espetáculos desenvolvem um tipo de realismo que não é da ordem da semelhança, subvertendo as hierarquias do sistema representativo, provocando desvios entre o real e o ficcional, entre o ordinário e o extraordinário. Os textos, que mais parecem um "testemunho biográfico", mesclam as palavras à música, no caso de $\mathrm{FH}$, e as palavras aos gestos, no caso da narrativa de DS, de tal forma que seria impossível dissocia-los, separando o texto de sua representação cênica. Como observa Josette Féral, a proposito do texto performativo, "se trata de un texto que muy a menudo no tiene autonomia propia, y cuyo sentido fraccionado raramente constituye una totalidade en sí. No tiene sentido sino atrapado en la red múltiple de los diferentes sistemas escénicos" (Féral, 2004, p. 109).

Esta demanda por uma expressão estética do cotidiano privado, além de ser uma reação ao ceticismo moderno, que como já descrito isolava (ou acreditava isolar) o fato teatral de seu contexto mais amplo - histórico, social, cultural e existencial -, coloca em questão as relações estabelecidas entre $o$ real e o artifício. $\mathrm{O}$ que defendemos aqui, tomando como exemplo estas duas experiências cênicas, é a presença de uma narrativa sedutoramente desviante da lógica representativa, mas que não nega sua potência em criar a ilusão, ao contrário, que se estabelece entre o real e o artifício, entre o fantástico e o crível. Percebe-se, o registro de uma teatralidade consciente, que tanto se afasta do cânone teatral (diálogos, personagens, conflito), para se deixar contaminar pelos gestos de autorrepresentação do performer, como, ao mesmo tempo, realiza uma cena que coloca em jogo essa "presença real" no uso de procedimentos artísticos, operando sedutoramente o real. Tal é o caso das duas peças aqui citadas. São espetáculos completamente diferentes, mas que se aliam no sentido de relacionar, em sua escritura, procedimentos teatrais e de performance.

No caso de "Preferiria não?", o texto narrativo é interpretado e dirigido pela atriz e performer Denise Stoklos, a partir de sua adaptação do conto "Bartleby, o Escriturário" do escritor norte-americano Herman Melville. Neste espetáculo observa-se que o impacto do real, a própria presença da performer, é atenuado por uma forte teatralidade, que mesclando aspectos ficcionais do conto a testemunhos biográficos da artista, embaralha ambos numa escritura que dá ao real um aspecto mais sedutor, na medida em que o desvia de sua identidade para destiná-lo ao jogo das estruturas simbólicas do teatro. Já no caso do espetáculo "Trilhas sonoras de amor perdidas", dirigido por Felipe Hirsch, com criação da Sutil Companhia ${ }^{2}$, observa-se uma intensificação do real, a partir da intensificação da palavra e da presença física do ator, Guilherme Weber, que permanece em cena três horas, ouvindo e discursando sobre trilhas sonoras dos anos 80 e 90. O texto, também narrativo, não se propõe a estabelecer uma situação dramática ipsis litteris, o que se passa no palco é uma cena construída a partir de uma situação que se

20 espetáculo foi o resultado de um processo de pesquisa sobre as histórias de Thurston Moore, Kim Gordon, Lee Ranaldo, Steve Shelley, Dean Wareham, Dan Graham, John Zorn, Jim O’ Rourke, Elizabeth Peyton, Arthur Jones, Jason Bitner, Rob Sheffield, Raymond Pettitbon, Greil Marcus, David Shields, Lou Reed, Giles Smith, entre outras. 
repete exaustivamente sobre ela mesma, mesclando palavras com músicas que estão afetivamente ligadas à vida do interprete. À diferença do espetáculo de DS, “Trilhas sonoras de amores perdidos" não se propõe a atenuar o real, e sim a intensificá-lo, usando da teatralidade, para sublinhar o que o real tem de obsessivo, repetitivo, verborrágico e instantâneo. O real é também aqui desviado pelo jogo instável entre teatralidade e performatividade, alcançando essa dimensão sedutora que nos instiga a pensar o contemporâneo.

Levando em conta o pressuposto de que ambos os espetáculos, em suas diferentes textualidades, nos ajudam a compreender aquilo que denominamos como realismo sedutor, que, por sua vez, é entendido aqui como uma possível tendência de teatralidade observada nas práticas cênicas contemporâneas; nestes dois exemplos destacados do teatro brasileiro, nos cabe ainda descrever o modo como cada um deles opera em simultaneidade o real e o artifício. Isto é, na interrupção do modo de produção do dramático, esses dois espetáculos operam um tratamento crítico ou estético do real, que os desviam da lógica representacional, sem darem as costas à ilusão, ao mistério, ao teatro, embriagando-se com elementos de performatividade. Ambos os espetáculos se situam longe da negação obsessiva da representação, do discurso ou da narrativa, ainda que estejam embriagados pelos gestos de autorrepresentação do performer.

Em "Preferiria não?", a performer Stoklos se põe a tarefa de narrar um episódio da vida de uma figura anônima e insignificante, o escriturário Bartleby, um homem-fantasma sem grandes ambições ou conflitos existências. Não se pode dizer que há uma situação dramática, o único motor da narrativa é a inusitada resposta negativa do homenzinho à tarefa diária de copiar: "preferiria não", diz o homenzinho sem maiores explicações. A simples recusa da tarefa por Bartleby muda a realidade desta figura insignificante, que ganha importância dramática na narrativa de Stoklos, que o apresenta a partir do estranhamento provocado pela inesperada negação de sua rotina diária. Se antes era invisível, a partir do estranhamento provocado pelo seu "preferiria não", Bartleby ganha uma existência ficcional onde é possível especular algo sobre ele, isto é, ele ganha a possibilidade de ter uma história, que pode ser inventada ou não, não importa. O que é importante é que Bartleby para sair do anonimato e da invisibilidade, precisa ser construído, ficcionalizado, pois só teatralizado, representado, é que Bartleby pode existir em cena, ter uma realidade, e nos causar algum efeito.

$\mathrm{O}$ que se intensifica na construção da narrativa por Stoklos é a própria ficcionalização de Bartleby que se confunde com os gestos autorrepresentativos de seu narrador. Trata-se em primeiro lugar da apresentação e constituição do personagem no palco, na cena, por meio dos gestos e do discurso reflexivo e autorreflexivo da performer, que se apresenta ao mesmo tempo como autor, ator, performer, espectador e encenador. $\mathrm{O}$ texto apresentado por DS não é uma peça e sim um texto no sentido que destacamos neste artigo: "Preferiria não?" se conforma no ato consciente do performer que opera o real produzindo outra realidade - um espaço de teatralidade; ou como quer Pavis, postulando um tratamento estético sobre o real; sem esquecer que a operação realizada por DS não se quer prisioneira de uma estrutura narrativa e representacional, pois seu texto realiza um jogo entre as estruturas de ficcionalização e os fluxos energéticos - vocais e gestuais - do ato performativo. Bartleby não é um personagem e DS não é a interprete de uma peça teatral, ambos se confundem e se mesclam numa perspectiva sedutora que nos impede de traçar uma nítida separação entre teatralidade e performatividade, entre ficção e movimentos autobiográficos performativos, conformando aquilo que denominamos conceitualmente como realismo sedutor.

Em "Trilhas sonoras de amor perdidas", que está bem mais próxima de uma 
estrutura teatral, no sentido de que se comunica por uma espacialidade ficcional mais elaborada e estratificada - cenário, figurino, interprete, encenador -, verificase a tentativa do teatro em orientar suas ações a partir de fluxos energéticos próprios à performatividade, promovendo assim a interrupção da lógica representacional, da síntese dramática, devedora da necessidade e verossimilhança. A verborragia sem pausas do texto, orientado pelos fluxos energéticos das trilhas sonoras, sua temporalidade estendida, repetindo obsessivamente a situação sobre ela mesma, de forma autista, sem obter uma solução, promovem fluxos de pensamento, desejo e memória, que incidem na teatralidade, sem rompê-la definitivamente, mas que enfatizam no texto seu caráter de performatividade. Ou seja, desprezando, ou deixando em segundo plano, o valor racional da síntese dramática, a partir desta intensificação do real na cena teatral, o espetáculo da Sutil Companhia experimenta no teatral o instantâneo e o não repetível das experiências sensoriais e energéticas. Como já destacado por Josette Féral, este tipo de espetáculo, que se deixa embriagar pela arte da performance, recebeu a nomenclatura de "teatro performativo". Porém o que nos instiga a pensar esses espetáculos é a possibilidade de abertura de uma via de confronto ao desencanto produzido pelas tentativas de apagamento da teatralidade, que, por uma estética do choque, da realização do real, ou pela obsessão de autonomia antimimética da obra, eliminou tanto o que havia de mistério no mundo, como eliminou a comunicação, o sentido, a troca simbólica: instituindo o que Baudrillard vai chamar de "apagamento do real".

Nos dois espetáculos analisados aqui, nos propomos a reconhecê-los como exemplos, no caso brasileiro, de diferentes textualidades, e modos de tratamento do real, que propõe um pensamento na arte a partir de um retorno do real na cena contemporânea, na conformação de um realismo mais afetivo. Pensar o real a partir de sua ficcionalização é a condição para o retor- no do real na cena contemporânea, em sua configuração sedutora, terreno instável do entrecruzamento entre o real e artifício, entre o teatral e a performatividade. $\mathrm{O}$ realismo sedutor nos embriaga de realidade, nos desviando do choque obsceno e sem encanto do real, nos seduzindo por aquilo que ele esconde, ou teatraliza. A cena do realismo sedutor reage contra toda forma imediata, sem distância, sem encanto, ele é a antítese da cena obscena. Para concluirmos, sem nos alongarmos demais, numa tentativa de tornar um pouco mais clara a perspectiva do realismo sedutor, convocamos o filósofo Baudrillard que no livro “Senhas" (2001) analisa a sedução enquanto uma operação oposta a toda tentativa de positivar o mundo e as coisas. Como afirma o pensador, pela sedução não queremos dominar ou expor a verdade, queremos coloca-la em jogo. Cobrir o real com um véu, afirma, é dar a ver sua potência. Para o filósofo, o questionamento radical da realidade pelo projeto antimimético modernista, "expulsando do real a ilusão e a utopia", teve como consequência a "desaparição do real" (Baudrillard, 1997, p. 92). Este "assassinato do real", engendrado por uma espécie de sobre-exposição do real, aniquiladora de todo mistério, enigma, ilusão e alteridade, é assim definido por Baudrillard: "o espetáculo tem ligação com a cena. Em compensação, quando se está na obscenidade, não há mais cena, jogo, o distanciamento do olhar se extingue. [...] a definição de obscenidade seria, pois, a de tornar real, absolutamente real, alguma coisa que até então era metafórica ou tinha uma dimensão metafórica" (2001, p. 29). A tentativa de eliminar a teatralidade, em prol de uma acentuação super-realista do real, eliminando a cena, o teatro, constituindo a experiência da presença pura, ocasionou aquilo que Baudrillard vai chamar de simulação desencantada. O pornô ou o obsceno é aquilo que descarta todo jogo, toda alteridade, todo segredo, em prol de uma realização.

Essa maximização da realidade elimina todo discurso que envolve o real e nos 
apresenta objetos e figuras sem referências, sem fundo, instituindo a presença, a pura aparência, nos intoxicando com um excesso de realidade, que, ao contrário de aprisionar o real, o faz desaparecer. Num mundo onde tudo é "imediatamente existente como realidade concreta [...] há, não uma comunicação, e sim uma "contaminação de tipo virótico, tudo passa de um para o outro de maneira imediata" - isto é, sem mediação, sem encanto, sem troca -; e continua o pensador: "Há, por um lado, uma arte capaz de inventar uma outra cena, que não a real, uma outra regra do jogo e, por outro lado, uma arte realista, que caiu em uma espécie de obscenidade, tornando-se descritiva, objetiva ou simples reflexo da decomposição - da fractalização do mundo" (2001, p. 31). A sedução, segundo Baudrillard, "é um desafio, uma forma que tende sempre a perturbar as pessoas no que se refere à sua identidade, ao sentido que esta pode assumir para elas. Elas aí reencontram a possibilidade de uma alteridade radical" (2001, p. 25).

Baudrillard corrobora com nosso pensamento, ao sustentar que: "no desfalecimento súbito da realidade e na vertigem de nela perder-se" (1997, p. 17) é que acontece o milagre. $\mathrm{O}$ milagre, momento em que o real se mostra, é quando o teatro assume uma posição intermediária, entre: onde o real e o convencional, a realidade e o artifício se encontram; um lugar de fronteira entre as margens do real e da fantasia. É nesse desvio do artefato, do signo puro, que o real pode retornar; é na sedução, no véu que encobre o real e que não o deixa aparecer demais, que ele se mostra em todo seu esplendor. 


\section{REFERÊNCIAS}

BAUDRILLARD, Jean. Senhas. Rio de Janeiro: Difel, 2007.

. A arte da desaparição. Rio de Janeiro: Ed. UFRJ, 1997.

CARLSON, Marvin. Performance, uma introdução crítica. Belo Horizonte: Ed. UFMG, 2009.

DELEUZE, Gilles. "Um manifesto de menos". In_ Sobre o teatro: um manifesto de menos; O esgotado. Roberto Machado (ORG). Rio de Janeiro: Zahar, 2010.

DERRIDA, Jacques. A escritura e a diferença. São Paulo: Perspectiva, 1971.

FÉRAL, Josette. Teatro, teoría y práctica: más allá de las fronteras. Buenos Aires, Galerna: 2004.

LEHMANN, Hans-Thies. Teatro Pós-Dramático. São Paulo: Cosac Naify, 2007.

"Teatro pós-dramático e teatro político". In_O Pós-Dramático. J. Guinsburg (ORG). São Paulo: Perspectiva, 2008.

PAVIS, Patrice. "La théâtralité en Avignon". In_ Voix et images de la scène. Vers une théorie de la pratique théâtrale. Villeneuve-dAs: Presses Universitaires du Septentrion, 2000.

. Dicionário de Teatro. São Paulo: Ed. Perspectiva, 1996.

RANCIÈRE, Jacques. A partilha do sensivel. São Paulo: Editora 34, 2009.

TASSINARI, Alberto. O Espaço moderno. São Paulo: Cosac \& Naify editores, 2001. 